\title{
Estudios de agenda setting en Cuba: propuesta de metodología para un desarrollo posible
}

\author{
Agenda setting studies in Cuba: proposal of methodology for a \\ possible development
}

\author{
Viviana MuñIZ ZÚNiga \\ Universidad de Oriente - Santiago de Cuba \\ YÁNDER CAstillo Salina \\ Universidad de Oriente - Santiago de Cuba \\ vivita@uo.edu.cu (CUBA)
}

Recibido: 13.06 .2017
Aceptado: 30.08 .2018

\section{RESUMEN}

Los nuevos escenarios mediáticos, el contexto social, económico y político del país, y la necesidad de transformar el modelo de prensa para dar mayor participación a la audiencia, hacen que en Cuba los estudios sobre agenda setting se hayan transformado a las circunstancias particulares que rigen el sistema nacional de medios. Una de las áreas en las cuales ha sido preciso introducir modificaciones es la metodología para profundizar en este proceso. Por ello el presente estudio tiene como objetivo Proponer una metodología para desarrollar estudios de agenda setting en Cuba a partir del análisis de las relaciones entre las agendas política, mediática y pública, y los factores que en ella inciden.La metodología se desarrolla en torno a tres áreas importantes para los estudios de agenda setting: la correlación estadística entre los objetos y atributos, las influencias sobre el contenido mediático, y las condiciones contingentes. Los principales aportes de la propuesta radican en la posibilidad de implementar investigaciones contextualizadas a la realidad cubana, cuyas características y evolución la convierten en un sistema complejo con determinadas particularidades. 


\title{
PALABRAS CLAVE
}

Agenda setting, influencias sobre el contenido de los medios, condiciones contingentes, correlación de agendas, propuesta metodológica.

\begin{abstract}
The new media scenarios, the social, economic and political context of the country, and the need to transform the press model to give greater participation to the audience, make in Cuba the studies on agenda setting have been transformed to the particular circumstances that govern The national media system. One of the areas in which changes have been made is the methodology to deepen this process. Therefore, the present study aims to propose a methodology to develop studies of agenda setting in Cuba based on the analysis of relations between political, media and public agendas, and the factors that affect it. The methodology is developed around three important areas for the agenda setting studies: the statistical correlation between the objects and attributes, the influences on the media content, and the contingent conditions. The main contributions of the proposal lie in the possibility of implementing contextualized research to the Cuban reality, whose characteristics and evolution make it a complex system with certain particularities.
\end{abstract}

\section{KEY WORDS}

Agenda setting, influences on the content of the media, contingent conditions, correlation of agendas, methodological proposal.

\section{INTRODUCCIÓN}

La relación entre las fuentes institucionales, los medios y la audiencia en Cuba deviene un fenómeno complejo a la luz de las particularidades del sistema mediático cubano y las transformaciones sociales producidas desde el año 2012, con la aprobación de los Lineamientos de la Política Económica y Social del Partido y La Revolución, y en el 2016, cuando se aprobaron la Conceptualización del modelo económico y social cubano de desarrollo socialista y el Plan nacional de desarrollo económico y social hasta 2030.

La sociedad cubana se caracteriza por una diversidad creciente desde lo socio-económico con la aparición de un sector no estatal de la economía, la emergencia pública de expresiones culturales y espirituales que pugnan por su presencia y reconocimiento en el espacio comunicacional, y las transformaciones a escala global de los sistemas comunicativos con la irrupción de las redes 
y soportes digitales que crean la posibilidad de democratizar la producción y el acceso a la información y a la producción cultural (Vidal, 2017).

En Cuba el trabajo de la prensa está básicamente regido por una Política Informativa, que no está contenida en un solo documento que resuma su grado de alcance; sino que es producto de directrices generales que sirven de guía para el trabajo de la prensa. Para Julio García (2018) cuando se habla sobre Política Informativa es preciso referirse a las relaciones entre el Partido, el Gobierno y los medios, la definición de deberes, derechos y atribuciones fundamentales de los actores del proceso informativo y el establecimiento en particular del marco de competencia de directores, ejecutivos y periodistas.

Estudios realizados en las universidades cubanas (Gallego y Rosabal, 2013; Quiala, 2015) han demostrado empíricamente que la relación temática entre los medios de comunicación y la audiencia es baja, debido principalmente a las características del proceso de construcción de las agendas mediáticas y la permanencia temporal de los temas en la agenda pública.

A nivel teórico la relación entre las fuentes, los medios y el público ha sido objeto de análisis de múltiples estudios, que enfocan el fenómeno con una mirada sociológica, psicológica, y comunicológica. Una de ellas es la agenda setting, que apunta hacia una ampliación y redefinición del papel tradicional de fijación de agenda de los medios de comunicación a partir de la influencia de fuentes externas, otros medios y la audiencia (McCombs, Shaw y Weaver, 2014; Aruguete, 2015).

¿Cómo es posible que en Cuba se haya aplicado una teoría surgida en condiciones políticas y sociales completamente diferentes? Para investigar sobre el tema se han adaptado los postulados generados en otros contextos, sobre todo porque la agenda setting se gestó en escenarios políticos que marcaron notablemente su alcance y metodología. Asimismo, ha sido preciso pensar la relación entre las agendas desde una perspectiva atemperada a las transformaciones y particularidades del modelo de prensa cubano, que actualmente demanda de nuevas miradas para una renovación que propicie un papel más activo de los medios en las transformaciones sociales.

Por tanto, la pertinencia de estudios que profundicen en la relación entre las agendas política, mediática y pública en Cuba se sustenta sobre tres elementos: las particularidades de la esfera pública cubana y las relaciones entre los actores sociales que en ella se establecen; las características contextuales y de funcionamiento de los medios de comunicación y sus formas de interacción con la agenda ciudadana y la necesidad de transformar las relaciones verticales existentes entre estas tres agendas en la esfera pública.

En este sentido se desarrolla el presente estudio, cuyo principal aporte radica en la propuesta de una metodología para llevar a cabo investigaciones sobre agenda setting en el país, tomando en cuenta las características del sistema mediático cubano y las relaciones contextuales entre medios y públicos. El trabajo pretende sistematizar los principales procedimientos utilizados para medir y correlacionar agendas y analizar las influencias en este fenómeno, con lo cual se contribuye a establecer pautas para futuras investigaciones en el país. 
Para ello se plantea como objetivo Proponer una metodología para desarrollar estudios de agenda setting en Cuba a partir del análisis de las relaciones entre las agendas política, mediática y pública y los factores que en ella inciden.

La propuesta metodológica toma como referente a los estudios de agenda setting realizados en el país desde 2010 hasta el 2015, y comenzó a desarrollarse en el 2016 con su aplicación posterior en varias investigaciones. Para una mayor generalización y confiabilidad fue validada por expertos cubanos y extranjeros.

\section{LA TEORÍA DE LA AGENDA SETTING: ENTRE LA EVOLUCIÓN Y LA TRADICIÓN INVESTIGATIVA.}

Desde que McCombs y Shaw (1972) llevaron a cabo su primer estudio sobre el establecimiento de agenda en Chapel Hill, Carolina del Norte, durante las elecciones presidenciales de 1968, la teoría de la agenda setting ha generado una gran cantidad de investigaciones que se han encargado, principalmente, de replicar las correlaciones entre las agendas mediáticas y públicas (Ghanem y Wanta, 2001), de identificar los factores que contribuyen a la formación de diferentes agendas (Fico y Freedman, 2001) y desarrollar formalmente y comprobar la teoría (McCombs y Shaw, 1993).

El estudio original de establecimiento de agenda (McCombs y Shaw, 1972) examinó las elecciones presidenciales en la localidad de Chapel Hill, en Carolina del Norte. Sin embargo, la teoría se ha aplicado no solo a este tipo de contextos, sino a una variedad de situaciones comunicativas que traspasan del dominio académico original (McCombs, 2006). Aunque el concepto de establecimiento de agenda se basó en la categoría de pseudoentorno de Lippmann (1922), McCombs y Shaw (1972) fueron los primeros en realizar un estudio empírico de la transferencia temática entre medios y públicos.

McCombs, Shaw y Weaver (2014), tres de las figuras más prominentes en el campo de estudio de la agenda setting, explican que la teoría se ha expandido hacia dos tendencias: una centrífuga, que se extiende a dominios más allá de la atención original hacia los asuntos públicos; y una tendencia centrípeta, que explica aún más los conceptos de la teoría de la fijación de la agenda.

La mayor potencialidad de la teoría radica en su capacidad de asimilar las interpretaciones provenientes de otras perspectivas que permiten analizar la relación entre medios y públicos de acuerdo con la complejidad que esta entraña. Sin embargo, posee, a nuestro criterio, tres puntos que tienden a ser polémicos en el análisis de la relación inter-agendas:

- Contexto: no se contextualiza el estudio de medios, audiencias, los procesos de construcción de las agendas, entre otros.

- Actores sociales: los sujetos sociales (personas, periodistas, medios, etc.) no son vistos desde sus particularidades, ni desde su capacidad para construir sentido a partir de las influencias del entorno. 
- Transformación: la teoría no busca transformar socialmente las relaciones descritas, asumiendo una postura descriptiva de la interacción entre las agendas.

\subsection{Los niveles de la agenda y factores que inciden en su relación.}

Las agendas, independientemente de su tipología, funcionan en dos niveles: el de reconocimiento (inclusión y jerarquización) del tema, y el de valoración del mismo. Esto se reconoce respectivamente como objetos y atributos (McCombs y Valenzuela, 2014). Si bien estos niveles se desarrollaron durante la primera década de las investigaciones sobre el tema, en el año 2012 Guo, McCombs, y Tien $\mathrm{Vu}$ (2012) anunciaron la existencia de un tercer nivel de agenda. El Network agenda setting Model (NAS por sus siglas en inglés) plantea que los medios digitales pueden agrupar una serie de objetos y atributos -o ambos por separado- e influir de forma simultánea en la audiencia.

Para relacionar ambos niveles en la teoría se suele emplear el cálculo de correlaciones estadísticas que permiten establecer cuán cercanos o no se encuentran dichas jerarquizaciones temáticas. Sin embargo, el estudio de la relación entre las agendas que interactúan en la esfera pública no podría concebirse únicamente a partir de las correlaciones estadísticas entre estas, que si bien posibilitan medir las relaciones asociativas entre las agendas, no explican íntegramente el proceso mediante el cual logran causar co-determinaciones entre las mismas.

La construcción de la agenda de los medios se analiza a partir de la influencia de fuentes políticas e institucionales, para lo cual se han utilizado dos modelos que explican niveles de influencia sobre el contenido mediático: el Modelo de las Capas de la Cebolla (McCombs, 1993) y el Modelo de Jerarquía de Influencias (Shoemaker y Reese, 2016).

Estas investigaciones se corresponden a la cuarta fase de desarrollo de la agenda setting, conocida como agenda building. Internacionalmente se han realizado acercamientos a la relación entre las fuentes políticas y los medios a partir de otras teorías como el Newsmaking, que profundizan en factores importantes para la producción periodística, como la precariedad e inseguridad laborales, la influencia de los índices de audiencia, el predominio de los intereses económicos y políticos sobre los intereses periodísticos, la falta de ética profesional, la falta de respeto a la autonomía de los profesionales, entre otros (Oller y Chavero, 2015).

El Modelo de jerarquía de influencias (Shoemaker y Reese, 2016) permite explicar cómo se conforma la agenda de los medios a partir de niveles mutuamente incluyentes entre sí: individual, de procedimientos de los medios, organizacional, las instituciones sociales y el sistema social. La jerarquía según la cual los autores disponen los elementos que influyen en el proceso de producción de noticias y en los contenidos que reciben las audiencias, se deja bien claro que el 
contenido de los medios es un producto socialmente creado, no un reflejo de una realidad objetiva.

Por otra parte, el estudio de las Condiciones contingentes en la teoría de la agenda setting se corresponde a la segunda etapa de investigaciones desarrolladas en torno a este campo, con un marcado enfoque psicológico y sociológico en cuanto a la relación entre las agendas mediática y pública. Las Condiciones contingentes permiten explicar cómo los medios de comunicación influyen en la jerarquización temática del público atendiendo a factores cognoscitivos, actitudinales y conductuales, cuya determinación ha evolucionado en tiempo (Casermeiro, 2004).

Esta perspectiva provee una concepción de la agenda pública como resultado de la influencia de varios factores o fuentes, sobre todo las agendas de los medios de comunicación (McCombs y Valenzuela, 2014), dotando a esta agenda de cierta autonomía en su formación, al establecer que no solo es resultado del contexto y los medios que la generan, sino del sentir y pensar de las personas respecto al entorno en el que viven. Variables como la necesidad de orientación, la comunicación interpersonal y el tipo de medios comenzaron a estudiarse de manera más temprana, de conjunto con otras como los tipos de temas, las variables demográficas, el nivel de interés por la información política, la credibilidad de los medios y la magnitud en el uso de estos.

\subsection{Metodología para determinar la relación inter-agendas en estudios de agenda setting.}

En los más de 40 años transcurridos desde la realización del estudio seminal de la agenda setting, el diseño de las investigaciones, las metodologías, y las técnicas de análisis de los datos han sido muy diversas. Para explicar este acápite tomamos como base la llamada Tipología de Acapulco, planteada por McCombs (1981) durante el congreso de la International Communication Association realizado en ese año. Esta explica las diferentes perspectivas metodológicas de los estudios de agenda, basándose en dos aspectos: el tipo de datos analizados en los medios y la información proveniente del público.

El modelo plantea que existen 4 tipos de estudios: el primero mide una cierta variedad de temas sobre los datos acumulados en el público; el segundo mide múltiples temas en individuos por separado; el tercero evalúa la cobertura de los medios de comunicación sobre un tema, en comparación con datos generales del público; y el cuarto estudia un tema específico en individuos por separado.

En lo que se refiere a la agenda de los medios, la metodología empleada es el análisis de contenido de uno o varios temas. Es común realizar un seguimiento cuantitativo de uno o varios aspectos que sean de interés para el investigador en los medios de comunicación o que vengan dados por la agenda pública (Aruguete, 2015).

Cuando se han agrupado los temas que han aparecido en el medio se suelen emplear categorías amplias para facilitar la inclusión de un subtema dentro de un 
objeto (Rodríguez, 2004). Esta técnica debe poder aplicarse a datos de similar naturaleza producidos en otros contextos, por otros investigadores, por lo cual es perfectamente manejable en los estudios de agenda (Valenzuela y Arriagada, 2009).

Sobre el tipo de medios manejados para hacer el seguimiento de cobertura, se destacan la prensa plana, como periódicos y revistas, aunque también se han medido las agendas de diferentes canales. Para la investigadora Raquel Rodríguez (2004: 45) "la radio ha sido uno de los medios más excluidos de los estudios de Agenda setting, porque esta teoría se desarrolla principalmente en Estados Unidos, país que no cuenta con un gran índice de audiencia radiofónica". Este criterio emitido hace más de 10 años es perfectamente comprobable en la actualidad, cuando existe una cifra relativamente baja de los estudios sobre agenda en emisoras radiales (Peña, 2015). De hecho, en las evaluaciones que se han realizado teniendo en cuenta la Intermedia Agenda setting (Stromback y Kiousis, 2010; Silva, 2015) se tienen como principales campos de recogida de información los canales de televisión, periódicos y agencias de prensa.

Por otra parte, para determinar la agenda pública se le realiza a la muestra escogida una pregunta abierta inicial del tipo PMI («¿cuál es el problema más importante sobre...?»), lo que genera una variedad de respuestas que orientan al investigador en el momento de elaborar el cuestionario «oficial» sobre el tema objeto de estudio (Casermeiro, 2004). Otro de los métodos aplicados para conocer los temas o subtemas que más interesan a la audiencia es el de puntuar los temas de una lista cerrada, procedimiento que tiene como inconveniente que las personas no suelen razonar en lo que marcan y ofrecen la respuesta que les viene primero a la mente (Muñiz, Fonseca y Castillo, 2015).

En cuanto a la agenda política, algunos estudios (Aelst, Thesen, Walgrave y Vliegenthart, 2014) han confirmado que posee dinámicas de funcionamiento diferenciadas de la agenda pública y mediática, aunque en un sentido generalizado las tres se relacionan con la relevancia temática. Walgrave y Aelst (2004) reflexionan sobre las opciones para medir la agenda política, insistiendo en que se deben determinar los niveles de gobierno a tener en cuenta, los temas en torno a los cuales se desarrollará el estudio, el período de tiempo a considerar, entre otros elementos relativos a la lógica gubernamental.

Para analizar los resultados se han empleado diferentes pruebas, destacando el uso de correlaciones estadísticas con una alta significación. Las medidas de asociación más empleadas han sido el Chi cuadrado y las correlaciones de Spearman y Pearson entre otras (Rodríguez, 2004). De igual modo se ha utilizado el estadístico Rozelle-Campbell baseline para correlacionar las agendas de forma cruzada, técnica que ha dado buenos resultados en los estudios de Intermedia Agenda setting, y otros en los que se quiere determinar la influencia inversa de una agenda sobre otra (Valenzuela y Arriagada, 2009).

El acercamiento a las condiciones contingentes también tuvo una base principalmente cuantitativa, al utilizar encuestas a grandes muestras para determinar variables como la necesidad de orientación, el interés por los temas políticos, el consumo de los medios, entre otras (Casermeiro, 2004). La construcción de la 
agenda mediática ha tenido una evolución más sociológica, pues los modelos más utilizados provienen de esta ciencia. Esta condición otorga un significativo matiz cualitativo a la aplicación de las técnicas. Sin embargo, a pesar de la creciente tendencia a profundizar en el fenómeno desde el punto de vista cualitativo, lo cierto es que la teoría refuerza aún la base positivista bajo la cual se desarrolló, lo que constituye una limitante en cuanto a la visión particularizada de sujetos, contextos y resultados en cada estudio.

\subsection{Caracterización del contexto político y mediático cubano.}

Cuba posee un proyecto de sociedad socialista o en transición al socialismo, que implica la autogestión o autogobierno en el marco de nuevas relaciones sociales. La participación del pueblo en las tareas estatales se efectúa mediante los órganos del Poder Popular, que se estructuran en la Asamblea Nacional -órgano supremo del poder del Estado y único con potestad constituyente y legislativa en la República- con su Consejo de Estado y las Asambleas provinciales y municipales, órganos superiores locales del poder estatal.La participación política se realiza a través de la multiplicación de roles, de forma tal que el ciudadano integra organizaciones de masas y políticas y desempeña a la vez otras ocupaciones (Guanche, Gentili y Saforcada, 2013).

El sistema mediático posee un alto grado de institucionalización: todos los medios se subordinan directamente al Partido Comunista de Cuba, que dirige en términos políticos de orientación, control, ayuda y trabajo con los cuadros de dirección, aunque cada órgano de prensa responde a una determinada organización o institución, con una dirección con las máximas atribuciones ejecutivas en la decisión de lo que se publica (García, 2013).

En el escenario mediático nacional confluyen medios estatales -que son la gran mayoría- con los llamados alternativos, financiados por instituciones extranjeras o cubanas, y cuya subordinación editorial es externa al Partido. Además, existen formas no legales pero generalizadas de distribución particulares de dichas agendas mediáticas a través del llamado paquete semanal: un compendio de materiales audiovisuales y escritos de procedencia extranjera o nacional, que es recopilado y distribuido a través de redes no institucionalizadas por todo el país.

Las particularidades de la esfera pública cubana indican una disfuncionalidad en la relación entre el sistema político, los medios y la sociedad (García, 2013), que se expresa a partir de la pobre participación del público en la conformación de las agendas mediáticas (Martínez y Dueñas, 2015) y la verticalización de los procesos de gestión, producción y socialización del material informativo, relacionada con la orientación excesiva de fuentes institucionales sobre el contenido mediático (Garcés y Senén, 2017).

El debate sobre la relación entre el sistema mediático y político ha transitado también por los marcos regulatorios de la prensa cubana, con escasa definición hasta el momento. En ese sentido, se aboga por la necesidad de establecer una 
Ley de Prensa y Comunicación que ampare el ejercicio del periodismo en Cuba, por dos razones principales: a) el Partido elabora la política, pero concretamente no tiene potestad legal para hacerla cumplir y b) la regulación de los medios no debe concentrarse únicamente en el marco de atribuciones del aparato partidista, porque el ejercicio regulatorio sobre los medios se expande más allá del Partido como organización y corresponde en esencia a la participación de los ciudadanos (Batista, 2013).

En el Proyecto Constitucional aprobado por la Asamblea Nacional de Poder Popular en el año 2018 -y en consulta popular entre los meses de agosto a noviembre de ese año-, se reconoce el derecho a "la libertad de pensamiento, conciencia y expresión", "a recibir del Estado información veraz, adecuada y oportuna" y se ratifica que los medios de comunicación social son de propiedad socialista de todo el pueblo. Sin embargo, se omiten las definiciones de derecho -a la información y a la comunicación-, lo que da cuenta de inconsistencias entre los documentos políticos aprobados en el mismo año, como la Política de Comunicación, la norma jurídica y las interpretaciones de estos.

Estos elementos permiten delimitar algunas particularidades del sistema mediático que necesitan una mirada diferente a partir de la teoría de la agenda setting, orientada hacia el análisis sociológico de las relaciones entre medios y audiencias y la evaluación cualitativa de fenómenos tan complejos como la construcción de las agendas mediáticas. El estudio del fenómeno en la Isla ha contribuido a la comprensión de la relación entre las fuentes institucionales, los medios y el público, a partir de profundizar en la cultura profesional de los periodistas, sus rutinas productivas, las particularidades del consumo mediático, principalmente con fines informativos, y la necesidad de orientación hacia la realidad del país.

\section{4. ¿Qué ha sucedido hasta el momento con los estudios de agenda en Cuba?}

Según Lugones y Saladrigas (2016) la investigación sobre Comunicación en Cuba ha tomado el matiz disciplinar del proceso comunicativo, a partir de dos vertientes: la búsqueda de datos empíricos y el análisis de los procesos comunicativos, y la necesidad de establecer perspectivas teóricas propias para la valoración de dichos procesos. En ese sentido, Saladrigas y Olivera (2011) señalan que la investigación en esta ciencia se realiza a partir de instituciones de Educación Superior, que diseñan espacios (como las tesis de pregrado, asignaturas curriculares, trabajos de curso) que permiten dar salida a las líneas investigativas.

Esta particularidad conlleva al hecho de que los estudios de agenda setting se concentren en las universidades, principalmente a nivel de pregrado, y se posicionen epistemológicamente desde la Comunicación, en una integración -no siempre efectiva- con la Sociología o la Psicología. A pesar de que las investigaciones sobre agenda en el país no responden a una línea articulada, se ha conso- 
lidado una metodología estable para determinar la relación entre los medios y el público, lo que no ha ocurrido en el caso de la agenda política.

En sentido general, se han utilizado técnicas provenientes del diseño cualitativo y cuantitativo, tendiendo a incluir las cualitativas en estudios sobre primer nivel. Lo anterior constituye una particularidad del caso cubano, lo que se debe de acuerdo con las condiciones coyunturales de la situación nacional. La siguiente tabla muestra un resumen de los resultados obtenidos de los estudios de agenda setting en Cuba y las técnicas utilizadas por nivel de investigación.

Tabla 1 Principales resultados y técnicas aplicadas según el nivel de investigación en estudios cubanos (Fuente: elaboración propia).

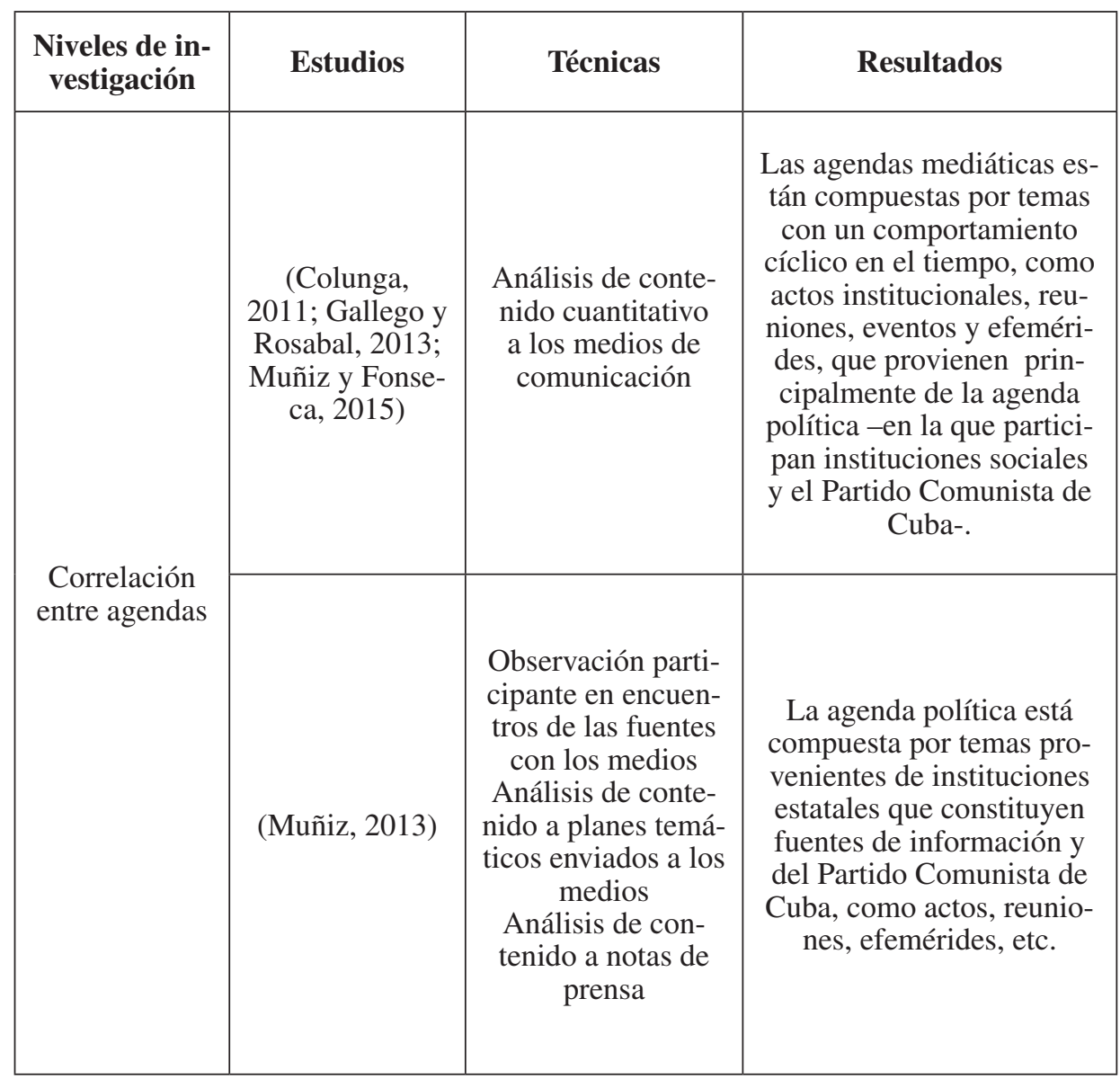




\begin{tabular}{|c|c|c|c|}
\hline $\begin{array}{l}\text { Niveles de in- } \\
\text { vestigación }\end{array}$ & Estudios & Técnicas & Resultados \\
\hline \multirow{3}{*}{$\begin{array}{l}\text { Correlación } \\
\text { entre agendas }\end{array}$} & $\begin{array}{c}\text { (Anazco, 2014; } \\
\text { Caballero, } \\
\text { 2015) }\end{array}$ & $\begin{array}{c}\text { Análisis de conte- } \\
\text { nido cuantitativo a } \\
\text { los boletines men- } \\
\text { suales que elabora } \\
\text { el Centro de Estu- } \\
\text { dios Sociopolíticos } \\
\text { y de Opinión del } \\
\text { Partido } \\
\text { Encuestas a la po- } \\
\text { blación }\end{array}$ & $\begin{array}{c}\text { La agenda pública está } \\
\text { compuesta por temas con } \\
\text { una permanencia estable, } \\
\text { que repercuten de alguna } \\
\text { forma en la vida material } \\
\text { de las personas, como el } \\
\text { transporte, la alimentación, } \\
\text { la vivienda, etc., que al no } \\
\text { tener una solución inme- } \\
\text { diata se reiteran constante- } \\
\text { mente. }\end{array}$ \\
\hline & $\begin{array}{c}\text { (Colunga, } \\
\text { 2011; Gallego y } \\
\text { Rosabal, 2013; } \\
\text { Quiala, 2015) }\end{array}$ & \multirow{2}{*}{$\begin{array}{l}\text { Correlación de } \\
\quad \text { Spearman } \\
\text { Estadístico Ro- } \\
\text { zelle-Campbell } \\
\text { Baseline }\end{array}$} & $\begin{array}{l}\text { Los medios no poseen una } \\
\text { relación temática con el } \\
\text { púbico desde el punto de } \\
\text { vista informativo, expresa- } \\
\text { do en las correlaciones no } \\
\text { significativas encontradas } \\
\text { que se mantienen estables } \\
\text { en el tiempo. }\end{array}$ \\
\hline & $\begin{array}{l}\text { (Castillo, 2015; } \\
\text { Muñiz y Fonse- } \\
\text { ca, 2015; Quia- } \\
\quad \text { la, 2015) }\end{array}$ & & $\begin{array}{l}\text { Las agendas mediáticas } \\
\text { poseen una relación mo- } \\
\text { derada o alta entre sí, lo } \\
\text { que permite plantear que } \\
\text { la agenda de los medios } \\
\text { no solo se repite, sino que } \\
\text { posee grandes similitudes } \\
\text { con las de otros medios a } \\
\text { nivel provincial y nacional }\end{array}$ \\
\hline
\end{tabular}




\begin{tabular}{|c|c|c|c|}
\hline $\begin{array}{l}\text { Niveles de in- } \\
\text { vestigación }\end{array}$ & Estudios & Técnicas & Resultados \\
\hline \multirow{3}{*}{$\begin{array}{l}\text { Influencias } \\
\text { sobre el con- } \\
\text { tenido de los } \\
\text { medios }\end{array}$} & $\begin{array}{l}\text { (Colunga, 2011; } \\
\text { Muñiz, 2013) }\end{array}$ & $\begin{array}{l}\text { Observación parti- } \\
\text { cipante a las ruti- } \\
\text { nas de producción } \\
\text { en los medios } \\
\text { Grupos de discu- } \\
\text { sión y entrevistas } \\
\text { a periodistas y di- } \\
\text { rectivos }\end{array}$ & $\begin{array}{l}\text { La construcción de las } \\
\text { agendas de los medios } \\
\text { se caracteriza por ser un } \\
\text { proceso vertical, donde las } \\
\text { fuentes institucionales le } \\
\text { proveen a la prensa objetos } \\
\text { y atributos a tratar en sus } \\
\text { coberturas, en detrimento } \\
\text { de asuntos de interés so- } \\
\text { cial. }\end{array}$ \\
\hline & $\begin{array}{c}\text { (Gallego y Ro- } \\
\text { sabal, 2013) }\end{array}$ & $\begin{array}{l}\text { Análisis de conte- } \\
\text { nido cuantitativo y } \\
\quad \text { cualitativo } \\
\text { Entrevistas a perio- } \\
\text { distas y directivos }\end{array}$ & $\begin{array}{c}\text { La jerarquización temática } \\
\text { está influenciada por el uso } \\
\text { de valores noticia, géneros } \\
\text { periodísticos y fuentes de } \\
\text { información determinados } \\
\text { por criterios de noticiabi- } \\
\text { lidad establecidos por los } \\
\text { medios, que funcionan de } \\
\text { forma homogénea en el } \\
\text { país. }\end{array}$ \\
\hline & $\begin{array}{l}\text { (Muñiz y Fon- } \\
\text { seca, 2015) }\end{array}$ & $\begin{array}{l}\text { Encuestas a perio- } \\
\text { distas } \\
\text { Correlación de } \\
\text { Spearman }\end{array}$ & $\begin{array}{l}\text { La agenda de los perio- } \\
\text { distas posee correlaciones } \\
\text { más elevadas con la agen- } \\
\text { da política y mediática, } \\
\text { que con la agenda pública. }\end{array}$ \\
\hline \multirow{3}{*}{$\begin{array}{l}\text { Condiciones } \\
\text { contingentes }\end{array}$} & $\begin{array}{c}\text { (Caballero, } \\
\text { 2015; Castillo, } \\
\text { 2015) }\end{array}$ & \multirow{3}{*}{$\begin{array}{l}\text { Encuestas a la po- } \\
\text { blación } \\
\begin{array}{c}\text { Grupos de discu- } \\
\text { sión }\end{array} \\
\begin{array}{l}\text { Observación parti- } \\
\text { cipante y no parti- } \\
\text { cipante }\end{array} \\
\text { Entrevistas }\end{array}$} & $\begin{array}{l}\text { Los hábitos de consumo } \\
\text { mediático con fines infor- } \\
\text { mativos están determinado } \\
\text { por elementos demográfi- } \\
\text { cos (edad, sexo, nivel edu- } \\
\text { cacional). }\end{array}$ \\
\hline & $\begin{array}{l}\text { (Caballero, } \\
\text { 2015) }\end{array}$ & & $\begin{array}{l}\text { Las personas suelen con- } \\
\text { formar su agenda atendien- } \\
\text { do primeramente a la fami- } \\
\text { lia y otros grupos sociales } \\
\text { a los que pertenecen, en } \\
\text { detrimento del uso de los } \\
\text { medios de comunicación. }\end{array}$ \\
\hline & $\begin{array}{l}\text { (Caballero, } \\
\text { 2015) }\end{array}$ & & $\begin{array}{l}\text { La necesidad de orien- } \\
\text { tación se proyecta hacia } \\
\text { temas tratados de alguna } \\
\text { forma por los medios y } \\
\text { con repercusiones materia- } \\
\text { les inmediatas. }\end{array}$ \\
\hline
\end{tabular}


Como se muestra en la tabla, existe una homogeneidad en algunos aspectos como las técnicas utilizadas para medir y correlacionar las agendas mediática y pública, y las empleadas para determinar los niveles de influencias sobre el contenido mediático. Existe mayor dispersión en cuanto a la medición de la agenda política, aspecto en el cual es preciso profundizar en las particularidades del sistema político y mediático en Cuba, y en el análisis de las condiciones contingentes. En cuanto a los medios más analizados han sido los impresos y la televisión y, en menor medida, los digitales, las agencias y la radio. Los medios de alcance nacionalson los más estudiados, principalmente los de prensa escrita y audiovisual, y aunque los de alcance provincial se analizan en menor cuantía, tienen una alta presencia en la investigaciones.

\section{PROPUESTA METODOLÓGICA PARA DESARROLLAR LOS ESTUDIOS DE AGENDA SETTING EN CUBA.}

La metodología que se propone para implementar estudios de agenda setting en Cuba cubre tres áreas fundamentales de este tipo de análisis: la correlación estadística de las agendas, la determinación de las influencias sobre el contenido de los medios y de las condiciones contingentes. La propuesta está basada en los siguientes principios que la caracterizan:

- Las condiciones contextuales del modelo de prensa cubano, y las particularidades de las agendas política, mediática y pública en relación con dicho contexto.

- Las posibilidades de articular las técnicas y métodos en los diferentes centros de producción científica encargados de investigar este tema en el país (específicamente las universidades).

- La necesidad de implementar diseños de investigación que permitan arribar a conclusiones en las que dialoguen elementos relacionados con la aplicación de instrumentos de diferentes tipologías y el análisis contextual que se hace de estos.

- El diagnóstico que se realice de estos elementos debe cumplir con cuatro características:

o Debe ser sistemático, teniendo en cuenta las características del objeto en constante cambiola recopilación del material debe efectuarse durante un período de tiempo más o menos amplio que posibilite establecer regularidades.

o Debe ser dinámico, para asumir las posibles variaciones del objeto en el tiempo y el contexto en que se inserta.

o Debe ser exhaustivo, para profundizar en las particularidades del fenómeno y sus posibles manifestaciones en la realidad.

o Debe tener un enfoque holístico en el que se reconozca al objeto como proceso complejo y dialéctico, si bien puede presentar un comportamiento relativamente estable durante largos periodos de tiempo. 


\subsection{Medición de la relación inter-agendas.}

La medición y correlación estadística comienza a partir de la determinación de las agendas que serán analizadas en el estudio, pues de este paso dependerá la utilización de las técnicas. Posteriormente es preciso elaborar el instrumento de medición, para lo cual pueden utilizarse como referencia aquellos objetos y atributos previamente evaluados por otras investigaciones cubanas (Colunga, 2011; Gallego y Rosabal, 2013; Quiala, 2015). Este proceso posee varias etapas: 1. Determinación preliminar de los objetos y atributos a medir:

- Aplicación de una prueba piloto en un medio de comunicación durante un mes como mínimo (se propone que se realice la prueba en la radio, por ser el medio con mayor cantidad de trabajos informativos por semana). Procesamiento de los datos obtenidos en la primera medición, lo que permite decantar aquellos objetos y atributos que no están presentes en la agenda de los medios.

- Aplicación de un sondeo de opinión (encuesta a una muestra no probabilística de la población) con la pregunta PMI abierta para determinar los temas que consideran como los más importantes desde el punto de vista experiencial (es preciso aclarar que se puede hacer la pregunta enfocada hacia diferentes alcances geográficos: nacional, provincial, municipal; pues los resultados serán similares).

2. Segunda aplicación del instrumento y comprobación de su validez: se recomienda aplicar el instrumento una segunda vez y correlacionar los datos obtenidos con los que se recogieron en la primera medición. De esta forma se puede determinar la validez interna del codificador (Hernández, Fernández y Baptista, 2014) utilizando un coeficiente de correlación: Spearman, Pearson, etc. 3. Medición de las agendas seleccionadas: una vez elaborado el instrumento se puede proceder a la aplicación del mismo a las agendas que se desea medir, teniendo en cuenta que la añadidura o retiro de los objetos y atributos debe realizarse en todos los casos, pues las correlaciones estadísticas se realizan solamente con elementos de la misma clase. Es recomendable que las agendas se midan en el mismo período de tiempo, que puede variar desde una semana, dos o tres meses o un año, y puede realizarse de forma transversal (con un solo tiempo de medición) o longitudinal (dejando un mes o dos en medio). La medición de las agendas durante semanas es aplicable en el caso de temas eventuales, que suelen aparecer repentinamente y luego disminuir en un período relativamente corto de tiempo. La medición durante dos o tres meses es útil para estudios transversales o longitudinales que posean meses intermedios de descanso. La medición durante un año puede realizarse a partir de la técnica de semana construida, para obtener un mayor nivel de aleatoriedad en la muestra y arribar a conclusiones más completas.

$\mathrm{Al}$ no existir un instrumento estandarizado para medir las agendas, se propone al menos la evaluación de los siguientes objetos que han tenido la mayor cantidad de menciones en los estudios realizados hasta el año 2016. La tabla muestra los objetos sugeridos en cada agenda, excluyendo las temáticas de cultura y 
deporte, que suelen aparecer solo en la agenda mediática y dificultan el cálculo de las correlaciones con otras agendas al soslayar la atención hacia objetos que realmente tienen una alta presencia cuantitativa. Este instrumento puede y debe ser enriquecido con otros objetos que el investigador incluya, así como los atributos que se estime medir en cada caso.

Tabla 2 Objetos sugeridos para realizar la medición de cada agenda en el caso cubano (Fuente: elaboración propia).

\begin{tabular}{|c|c|c|}
\hline Agenda mediática & Agenda política & Agenda pública \\
\hline $\begin{array}{c}\text { Actividades políticas, institu- } \\
\text { cionales y sociales }\end{array}$ & $\begin{array}{c}\text { Actividades políticas, institu- } \\
\text { cionales y sociales }\end{array}$ & $\begin{array}{c}\text { Servicios e instituciones } \\
\text { estatales }\end{array}$ \\
\hline Historia & Historia & Higiene comunal \\
\hline Salud pública & Gobierno & Comercio interior \\
\hline $\begin{array}{c}\text { Agricultura } \\
\text { Industria } \\
\text { tales }\end{array}$ & Higiene comunal & $\begin{array}{c}\text { Vivienda, construcción } \\
\text { y patrimonio }\end{array}$ \\
\hline $\begin{array}{c}\text { Industria } \\
\text { menio }\end{array}$ & Pransporte \\
\hline $\begin{array}{c}\text { Viviendica } \\
\text { monio }\end{array}$ & Educación & Acueducto pública \\
\hline Comunicaciones & Ciencia y tecnología & Problemas sociales \\
\hline Educación & Comunicaciones & Energía \\
\hline Política & & Gatronomía \\
\hline
\end{tabular}

A continuación se explica la propuesta para medir cada agenda (política, mediática y pública):

a. Agenda política: La agenda política en Cuba funciona en dos niveles. El primero de ellos es conceptual el cual conforma la base cultural a partir de la cual se establecen principios regulatorios a nivel macro. Por ejemplo, en este aspecto se destaca la Política Informativa, la Política Editorial, los documentos que regulan el trabajo de la prensa cubana, etc. En un segundo nivel, más aplicativo, se encuentran las estructuras encargadas de hacer cumplir esas regulaciones, por ejemplo, el Partido Comunista de Cuba a nivel nacional y sus respectivos Comités Provinciales, las instituciones sociales, etc. Este nivel permite que los temas pasen de la agenda política hacia la mediática y la pública -o se nutran de ellas-, pues se encuentra más cercanos al trabajo que realizan los medios de comunicación. 
En ambos casos, se recomienda medir esta agenda a partir de la dimensión aplicativa, o sea, lo que exteriorizan las fuentes y el Partido. Para ello, se puede aplicar un análisis de contenido a los planes temáticos que envía el Partido para su publicación, y la observación participante en las reuniones que hacen con los medios. Además, se deben tener en cuenta las notas de prensa y comunicados individuales o colectivos.

b. Agenda mediática: La agenda mediática puede ser medida a través del análisis de contenido a los productos informativos publicados en los medios de comunicación. Algunos estudios (Gallego y Rosabal, 2013) han demostrado que no es preciso conformar varios listados de jerarquización (según el espacio-duración, aparición en titulares y frecuencia de mención), porque estos poseen altas correlaciones estadísticas entre sí. Por esta razón se propone determinar la agenda de los medios a partir de la frecuencia observada de los objetos y atributos en cada órgano de prensa evaluado.

Cuando la agenda mediática sea de un órgano de prensa digital se recomienda aplicar un análisis de contenido computarizado, que permite recuperar los objetos y atributos de toda la página o de las secciones que se necesiten. A criterio de los autores, la subordinación editorial del medio no determina la técnica a utilizar para medir su agenda, aunque influya en otros niveles del proceso de construcción.

c. Agenda pública: Para la medición de la agenda pública existen varias técnicas que pueden ser utilizadas, pues el criterio de medida se encuentra mejor definido por la teoría. En esta propuesta se incluye la aplicación de al menos tres técnicas: encuestas, análisis de contenido y grupos de discusión o entrevistas. En este caso se combinan técnicas cuantitativas y cualitativas por dos razones: al no existir en todos los casos mecanismos encuestadores viables para llevar a cabo la pregunta PMI a una muestra probabilística de la población, esta se aplica principalmente a muestras no probabilísticas, lo que de cierta manera vulnera la validez del instrumento. Por otra parte, la utilización de los grupos de discusión y las entrevistas permiten establecer las causas de la jerarquización temática, cuestión relevante para lograr un nivel más profundo de compresión del fenómeno.

Una vez que se obtengan las agendas (a partir de la distribución de frecuencias absoluta y relativa) se puede proceder a la correlación estadística entre ellas, bien de forma directa (entre dos agendas durante un solo período de tiempo), o bien de forma cruzada inversa (entre dos agendas durante dos períodos de tiempo, en estudios de tipo panel o de series temporales).Se estima pertinente el uso del coeficiente de correlación de Spearman por el tipo de variables que se manejan en el caso de las agendas estudiadas, y porque ha sido el más utilizado y efectivo en las investigaciones de este tipo que fueron consultadas (Casermeiro, 2004; McCombs y Valenzuela, 2014). 


\subsection{Determinación de las Influencias sobre el contenido de los medios.}

En Cuba se han introducido algunos elementos que resultan de vital importancia en la comprensión de la construcción de la agenda mediática, realizados principalmente por el investigador Julio García Luis (2013), quien establece dos macro categorías que pueden fusionarse con las planteadas por Shoemaker y Reese (2016) en el Modelo de jerarquía de influencias: regulación y autorregulación de la prensa. La regulación "actúa sobre los contenidos de la prensa de manera indirecta, al influir en el contexto de la comunicación, es decir su entorno, sus condiciones, sus compromisos políticos, sus marcos legales, económicos, culturales y de otro tipo" (García, 2013:81).

En tanto, la autorregulación: "actúa sobre los contenidos de forma directa, mediante los instrumentos normativos y de funcionamiento interno de los medios, es decir, las estructuras de dirección y sus atribuciones de poder, la planificación del trabajo, las definiciones de las coberturas, los procesos de elaboración y edición de los mensajes, y la aplicación de las acciones concernientes a la cultura profesional" (García, 2013:81).

Tomando en consideración estos elementos, se propone el estudio de las mediaciones en el contenido del producto mediático a partir de los siguientes aspectos por niveles macro:

- Niveles de regulación: se analizan el papel de las instituciones sociales en la conformación de las agendas mediáticas y las características del sistema mediático en la esfera pública, incluyendo el rol de la audiencia en el establecimiento de esta jerarquización temática.

- Niveles de autorregulación: analiza la actividad realizada por los periodistas y directivos del medio de comunicación para garantizar la estabilidad de su funcionamiento interno. Se incluyen la cultura profesional, las rutinas productivas, las características organizacionales, etc.

En este caso, se sugiere a los investigadores que evalúen estos aspectos mientras se realiza la medición cuantitativa (si la hubiese), pues ello permite comprender mejor el fenómeno desde los actores sociales que en él intervienen. El procedimiento es acertado tanto para diseños mixtos como para los cualitativos y el período de tiempo depende del propio proceso de recopilación de los datos. La siguiente tabla muestra los niveles analizados en el proceso de construcción de la agenda, las respectivas técnicas que pueden utilizarse y las sugerencias de posibles preguntas para analizar cada nivel. 
Tabla 3 Niveles de influencia sobre el contenido mediático y técnicas para su determinación en Cuba (Fuente: elaboración propia).

\begin{tabular}{|c|c|c|c|}
\hline Niveles macro & Niveles específicos & Técnicas & $\begin{array}{c}\text { Sugerencias para } \\
\text { interrogantes }\end{array}$ \\
\hline \multirow{3}{*}{$\begin{array}{l}\text { Autorregula- } \\
\text { ción }\end{array}$} & $\begin{array}{l}\text { Nivel individual: } \\
\text { opinión sobre la } \\
\text { profesión; opciones } \\
\text { de superación y ne- } \\
\text { cesidad de hacerlo; } \\
\text { agenda temática de } \\
\text { los periodistas. }\end{array}$ & $\begin{array}{c}\text { Entrevistas } \\
\text { Encuestas (para } \\
\text { medición de agen- } \\
\text { da de los periodis- } \\
\text { tas y caracteriza- } \\
\text { ción demográfica } \\
\text { de la muestra). }\end{array}$ & $\begin{array}{c}\text { ¿Qué piensan los } \\
\text { periodistas sobre } \\
\text { su profesión? } \\
\text { ¿Qué función so- } \\
\text { cial le atribuyen al } \\
\text { periodismo que se } \\
\text { realiza en Cuba? } \\
\text { ¿Poseen alguna } \\
\text { militancia polí- } \\
\text { tica? } \\
\text { ¿En qué rango eta- } \\
\text { rio se encuentran? }\end{array}$ \\
\hline & $\begin{array}{l}\text { Nivel de procedi- } \\
\text { mientos de los me- } \\
\text { dios: conocimiento } \\
\text { de la Política Infor- } \\
\text { mativa y Editorial } \\
\text { (se puede determinar } \\
\text { con una sola pregun- } \\
\text { ta), participación en } \\
\text { la elaboración de los } \\
\text { planes temáticos del } \\
\text { medio, procedimien- } \\
\text { tos para la gestión, } \\
\text { producción y sociali- } \\
\text { zación de los trabajos } \\
\text { periodísticos, uso de } \\
\text { los valores noticia } \\
\text { y géneros periodís- } \\
\text { ticos. }\end{array}$ & $\begin{array}{l}\text { Análisis de conte- } \\
\text { nido cuantitativo } \\
\text { (para uso de valo- } \\
\text { res noticia, fuentes } \\
\text { de información y } \\
\text { géneros). } \\
\text { Grupos de discu- } \\
\text { sión } \\
\text { Entrevista }\end{array}$ & $\begin{array}{c}\text { ¿Qué pautas edi- } \\
\text { toriales siguen los } \\
\text { periodistas para } \\
\text { realizar su trabajo? } \\
\text { ¿Cómo se realiza } \\
\text { la planificación } \\
\text { del medio? } \\
\text { ¿Cómo partici- } \\
\text { pan y permiten } \\
\text { que otros actores } \\
\text { participen en la } \\
\text { construcción de la } \\
\text { noticia? }\end{array}$ \\
\hline & $\begin{array}{l}\text { Nivel organizacional: } \\
\text { estructura organizati- } \\
\text { va del medio; grado } \\
\text { de intercambio con } \\
\text { los directivos; grado } \\
\text { de preparación de } \\
\text { estos para realizar las } \\
\text { tareas de dirección; } \\
\text { indicadores demo- } \\
\text { gráficos (tiempo de } \\
\text { trabajo y militancia } \\
\text { en organizaciones } \\
\text { políticas). }\end{array}$ & $\begin{array}{c}\text { Entrevista } \\
\text { Grupos de discu- } \\
\text { sión }\end{array}$ & $\begin{array}{c}\text { ¿Cómo es la re- } \\
\text { lación entre los } \\
\text { periodistas y sus } \\
\text { directivos? } \\
\text { ¿Qué grado de } \\
\text { participación tie- } \\
\text { nen en la toma de } \\
\text { decisiones orga- } \\
\text { nizacionales y/o } \\
\text { editoriales? }\end{array}$ \\
\hline
\end{tabular}




\begin{tabular}{|c|c|c|c|}
\hline Niveles macro & Niveles específicos & Técnicas & $\begin{array}{c}\text { Sugerencias para } \\
\text { interrogantes }\end{array}$ \\
\hline \multirow[t]{2}{*}{ Regulación } & $\begin{array}{c}\text { Instituciones socia- } \\
\text { les: relación con el } \\
\text { Partido y otras fuen- } \\
\text { tes políticas o insti- } \\
\text { tucionales; relación } \\
\text { con el público; grado } \\
\text { de intercambio con } \\
\text { otras agendas para } \\
\text { conformar la agenda } \\
\text { mediática; uso de las } \\
\text { fuentes de informa- } \\
\text { ción. }\end{array}$ & $\begin{array}{l}\text { Entrevista (a perio- } \\
\text { distas y fuentes de } \\
\text { información) } \\
\text { Observación parti- } \\
\text { cipante } \\
\text { Grupos de discu- } \\
\text { sión }\end{array}$ & $\begin{array}{c}\text { ¿Cómo es la re- } \\
\text { lación entre los } \\
\text { periodistas y sus } \\
\text { fuentes? } \\
\text { ¿Qué criterios } \\
\text { utilizan para selec- } \\
\text { cionarlas y cuales } \\
\text { emplean con ma- } \\
\text { yor frecuencia? } \\
\text { ¿Hasta qué punto } \\
\text { la fuente intervie- } \\
\text { ne en la construc- } \\
\text { ción de la infor- } \\
\text { mación? } \\
\text { ¿Cómo participa } \\
\text { el público en la } \\
\text { conformación de } \\
\text { la agenda del me- } \\
\text { dio? }\end{array}$ \\
\hline & $\begin{array}{c}\text { Sistema social: con- } \\
\text { cepciones ideológi- } \\
\text { cas específicas sobre } \\
\text { el periodismo que se } \\
\text { hace en el país; con- } \\
\text { texto socio-político } \\
\text { en que se inserta el } \\
\text { medio de comunica- } \\
\text { ción. }\end{array}$ & $\begin{array}{l}\text { Entrevista } \\
\text { Observación parti- } \\
\text { cipante }\end{array}$ & $\begin{array}{l}\text { ¿En qué contexto } \\
\text { (social, histórico, } \\
\text { político, tecnoló- } \\
\text { gico) se insertan } \\
\text { los medios de co- } \\
\text { municación? } \\
\text { ¿Cómo influye } \\
\text { ese contexto en } \\
\text { la ideología pre- } \\
\text { dominante en los } \\
\text { periodistas? }\end{array}$ \\
\hline
\end{tabular}

Esta propuesta puede aplicarse en medios tradicionales y digitales estatales, y en medios digitales alternativos (no estatales), pues lo que varía en cada caso es la subordinación editorial, que a su vez determina la formación de otra cultura y rutinas de producción. También puede aplicarse en el caso del análisis de temas eventuales en las agendas, como parte del cual se podrían incluir aspectos como la implicación del periodista con el hecho como parte de un contexto social, cultural y geográfico afectado, la modificación de las rutinas y la organización del medio ante estos fenómenos, etc.

Por último, se considera indispensable establecer procesos de inmersión analítica en cuanto a la evaluación integral de los fenómenos descritos, para el entendimiento de los niveles de construcción del contenido de los medios. Estos deben orientarse a la delimitación de cuáles son prácticas profesionales y las 
relaciones al interior de los medios como manifestación de la cultura profesional propias de cada institución, y cuáles aspectos se manifiestan como consecuencia de la influencia de factores generales como pueden ser las políticas informativas establecidas para todo el sistema comunicativo nacional. Este análisis posibilitará la comprensión de las diferencias temáticas y profesionales entre medios diversos, aunque no se pueden perder de vista las características homogéneas del modelo de prensa cubano.

\subsection{Determinación de las Condiciones contingentes.}

Al considerar el amplio número de variables reconocidas en el análisis de la relación entre medios y públicos (Casermeiro, 2004; Rodríguez, 2004), en esta investigación se establecieron dos subdimensiones fundamentales según los autores: una de orientación psicológica y otra sociológica, ajustadas a las particularidades del campo de acción e intereses del estudio.

En ese sentido se identifican como los factores psicológicos aquellos elementos que desde la subjetividad, tanto individual como colectiva, inciden en los modelos conductuales y la capacidad perceptiva, cognitiva, interpretativa, actitudinal y motivacional de las personas, en cuanto a los temas que deben atenderse personal y públicamente, según el grado de prioridad otorgado a los mismos. Los elementos aquí relacionados son la necesidad de orientación, el interés por la información, las experiencias personales y/o sociales, y el tipo o naturaleza de los temas.

Por otra parte, los factores sociológicos constituyen condiciones objetivas o características socio-comunicativas, económicas, culturales, demográficas, políticas integradas como parte del desarrollo dialéctico de cada sistema social y los procesos de selección temática de los públicos. En esta dimensión se agrupan las variables demográficas, la comunicación y relaciones interpersonales, y la exposición y consumo de los medios de comunicación.

En este sentido se recomienda el uso de la encuesta para determinar: (1) los temas hacia los cuales los sujetos muestran mayor interés, (2) la frecuencia de uso de los medios de comunicación con fines informativos, (3) la frecuencia de intercambio sobre esos temas, (4) la jerarquización de las fuentes utilizadas para informarse sobre esos temas, (5) el comportamiento de las variables demográficas edad, sexo, nivel de escolaridad, etc. y su relación con otras variables (para ello las otras variables deben haber sido cuantificadas con el mismo instrumento).

Asimismo, se propone el empleo de técnicas cualitativas, como los grupos de discusión, las entrevistas y la observación participante como punto de contrastación de los resultados cuantitativos encontrados. Dicha triangulación metodológica brinda la posibilidad de obtener datos más completos, verificables y generalizables, en la medida en que igualmente se seleccionen correctamente las muestras de estudio y se utilicen técnicas estadísticas que permitan determinar su grado de relación. 
La duración temporal del análisis depende de la aplicación de las técnicas y la recuperación de los datos en cada caso. Se puede realizar de forma paralela a la medición de las agendas desde el punto de vista cuantitativo (si fuese necesario). Para la realización de los grupos de discusión se propone utilizar técnicas participativas y juegos que propicien un intercambio más fluido entre el investigador y los sujetos.

Tabla 4 Condiciones contingentes y técnicas para su determinación en el caso cubano (Fuente: elaboración propia).

\begin{tabular}{|c|c|c|}
\hline $\begin{array}{l}\text { Condición contin- } \\
\text { gente }\end{array}$ & Técnicas & $\begin{array}{c}\text { Sugerencias para in- } \\
\text { terrogantes }\end{array}$ \\
\hline $\begin{array}{l}\text { Necesidad de } \\
\text { orientación }\end{array}$ & $\begin{array}{l}\text { Encuesta (para determinar los pro- } \\
\text { blemas más importantes para las } \\
\text { personas y aquellos sobre los cuales } \\
\text { necesitan una mayor cantidad de in- } \\
\text { formación) } \\
\text { Grupos de discusión }\end{array}$ & $\begin{array}{c}\text { ¿Qué temas provincia- } \\
\text { les o nacionales nece- } \\
\text { sitan mayor cobertura } \\
\text { mediática? } \\
\text { ¿Sobre qué aspectos } \\
\text { de estos temas nece- } \\
\text { sita mayor informa- } \\
\text { ción? } \\
\text { ¿Por qué prestan aten- } \\
\text { ción a estos temas? }\end{array}$ \\
\hline $\begin{array}{l}\text { Interés por la in- } \\
\text { formación }\end{array}$ & $\begin{array}{c}\text { Encuesta } \\
\text { Grupos de discusión }\end{array}$ & $\begin{array}{c}\text { ¿Qué hacen cuando } \\
\text { consideran importante } \\
\text { un tema de su provin- } \\
\text { cia o país? }\end{array}$ \\
\hline $\begin{array}{l}\text { Consumo de los } \\
\text { medios/ tipos de } \\
\text { medios }\end{array}$ & $\begin{array}{c}\text { Encuesta } \\
\text { Grupos de discusión } \\
\text { Observación participante }\end{array}$ & $\begin{array}{l}\text { ¿Qué opinan del tra- } \\
\text { bajo de los medios } \\
\text { de comunicación en } \\
\text { la provincia? ¿Se in- } \\
\text { forman u orientan a } \\
\text { través de ellos? } \\
\text { ¿Qué medios prefieren } \\
\text { para informarse? }\end{array}$ \\
\hline $\begin{array}{l}\text { Relación entre el } \\
\text { tipo de temas con } \\
\text { las experiencias } \\
\text { personales de los } \\
\text { sujetos }\end{array}$ & $\begin{array}{c}\text { Entrevistas } \\
\text { Grupos de discusión } \\
\text { Observación participante }\end{array}$ & $\begin{array}{l}\text { ¿Cuán importante } \\
\text { consideran las con- } \\
\text { diciones en las que } \\
\text { viven actualmente } \\
\text { dentro de sus priorida- } \\
\text { des diarias? }\end{array}$ \\
\hline
\end{tabular}




\begin{tabular}{|c|c|c|}
\hline $\begin{array}{c}\text { Condición contin- } \\
\text { gente }\end{array}$ & Técnicas & $\begin{array}{c}\text { Sugerencias para in- } \\
\text { terrogantes }\end{array}$ \\
\hline $\begin{array}{c}\text { Características de } \\
\text { la comunicación } \\
\text { interpersonal }\end{array}$ & $\begin{array}{c}\text { Observación participante } \\
\text { Grupos de discusión } \\
\text { len conversar y co- } \\
\text { mentar acerca de esos } \\
\text { temas que consideran } \\
\text { importantes? } \\
\text { ¿Con quién lo co- } \\
\text { mentan? ¿Con qué } \\
\text { frecuencia debaten } \\
\text { sobre los temas más } \\
\text { importantes? }\end{array}$ \\
\hline $\begin{array}{c}\text { Contexto en que } \\
\text { surge la agenda }\end{array}$ & Observación participante & $\begin{array}{c}\text { ¿Cómo es su experiencia } \\
\text { en el lugar donde reside? } \\
\text { ¿Por lo general las } \\
\text { personas que lo } \\
\text { rodean necesitan estar } \\
\text { informados? }\end{array}$ \\
\hline $\begin{array}{c}\text { Variables } \\
\text { demográficas. }\end{array}$ & Encuesta & $\begin{array}{c}\text { Edad, sexo, lugar en que } \\
\text { reside, ocupación. nivel } \\
\text { educacional* }\end{array}$ \\
\hline
\end{tabular}

*Se pueden utilizar las variables demográficas que investigador convenga, y estas pueden ser analizadas en función de generar inferencias estadísticas con el cálculo del Chi cuadrado u otras medidas de asociación.

\subsection{Validación de la propuesta metodológica.}

Una de las formas utilizadas para validar la propuesta fue el criterio de expertos, lo que permitió reajustar y transformar la metodología a partir de las sugerencias emitidas. La selección del grupo de expertos se realizó teniendo en cuenta los criterios de Landeta (1999), quien plantea que la cantidad debe oscilar entre 7 y 30 sujetos.

El primer paso para realizar la validación fue fijar como criterio fundamental de la selección de los candidatos su grado de competencia expresado a partir del vínculo a las áreas de interés, el grado científico (relacionado con las ciencias afines al objeto de estudio: Comunicación Social, Sociología, Ciencias Políticas, etc.) y la experiencia profesional superior a los 5 años. El grupo quedó conformado por 9 expertos, entre los cuales se encontraban los siguientes investigadores cubanos y extranjeros. 
María Margarita Alonso (Cuba)
José Raúl Gallego Ramos (Cuba)
Carlos Muñiz Muriel (España)
José Ramón Vidal (Cuba)
Natalia Aruguete (Argentina)
Martín Oller Alonso (España)
Dasniel Olivera Pérez (Cuba)
Roger Ricardo Luis (Cuba)
Hilda Saladrigas Medina (Cuba)

El segundo paso fue la determinación del Coeficiente de Competencia (K) a partir del cálculo de los Coeficientes de Conocimiento (kc) y de Argumentación (ka) a la selección realizada, cuyos coeficientes fueron Altos y Medios entre los rangos $0,75<\mathrm{K}<1,0$.

Posteriormente el modelo propuesto fue sometido al grupo de expertos mediante un instrumento constituido por 12 indicadores que evalúan en una escala Likert de 5 ítems los elementos relacionados con la relevancia de la propuesta, su pertinencia para el contexto cubano y la teoría de la Agenda Setting, la posibilidad de aplicar la metodología en el país, las categorías utilizadas para denominar los elementos de la agenda política, etc. Para el procesamiento estadístico de la información se calculó la media aritmética de los valores, lo que permitió determinar el criterio generalizado respecto a cada indicador. Según el cálculo de la media aritmética, todos los ítems que forman parte del cuestionario fueron evaluados de Muy Adecuado o Bastante Adecuado, como se observa en la tabla siguiente: 


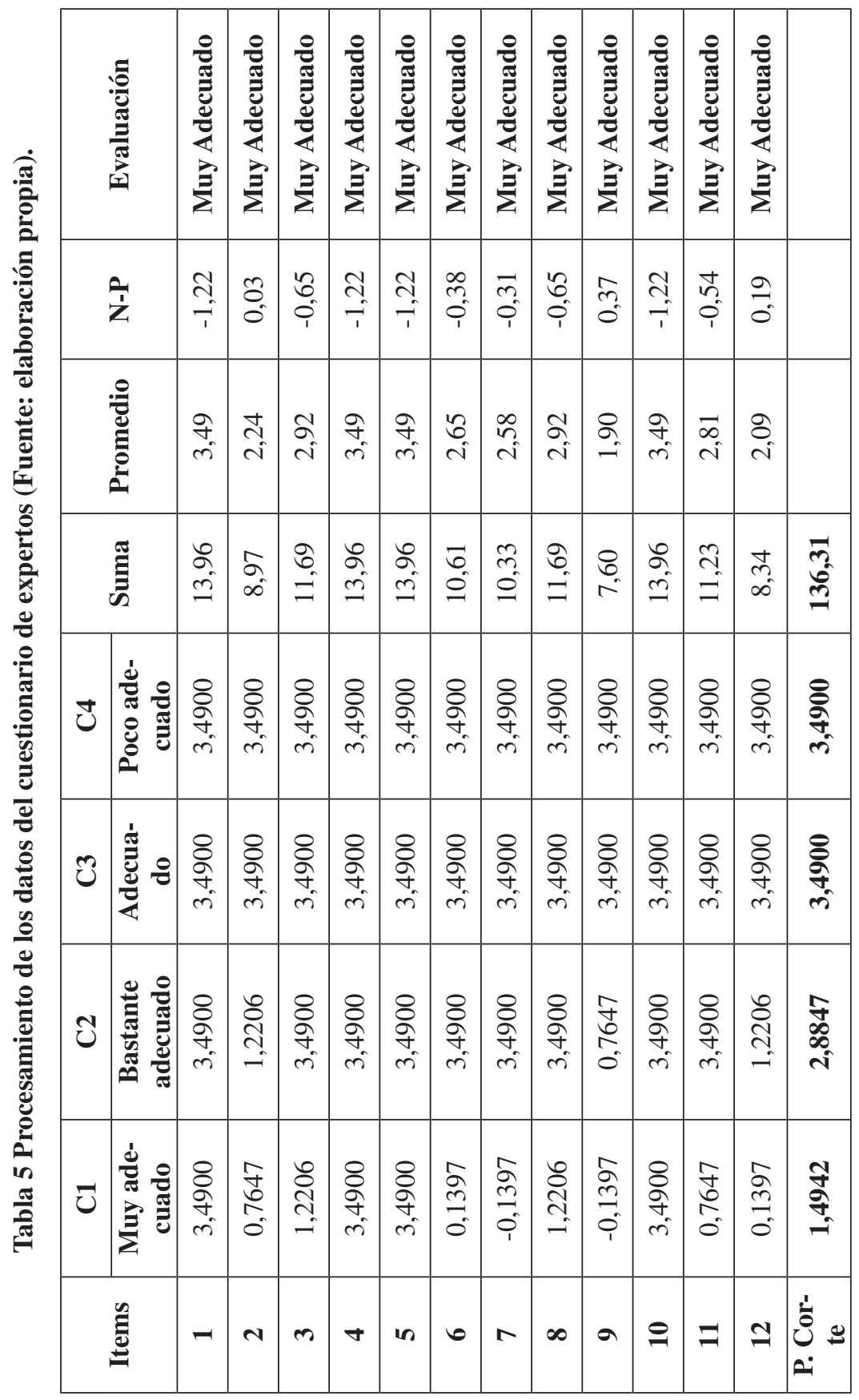


En cuanto a las sugerencias realizadas, uno de los expertos señaló que "al socializar el resultado de la investigación, debe hacerse en 3 etapas: con los profesionales del periodismo, decisores de la labor informativa y entre ambos, para a partir de criterios diversos e incluso "encontrados", establecer desde la teoría y la praxis periodística la realidad del fenómeno comunicológico". Otro experto argumentó que la metodología "propone una visión compleja considerando los actores políticos y mediáticos fundamentales, así como las expresiones profesionales características del contexto cubano. Dado el carácter homogéneo de las estructuras institucionales de la política y los medios podría tener potencialidad explicativa para el contexto cubano en general".

La segunda forma de validación fue la aplicación de la metodología para realizar estudios concretos (Gutiérrez, 2017; Ramos, 2017; Lasalle, 2017; Balben, 2018) en diferentes provincias cubanas como Santiago de Cuba y Guantánamo, y analizar el comportamiento de agendas mediáticas con diferente grado de alcance (nacional, provincial, local). Estos estudios permitieron ajustar aspectos importantes de la metodología, como el uso de técnicas cualitativas para evaluar la agenda pública, el procedimiento para calcular las correlaciones estadísticas y para determinar las condiciones contingentes.

\subsection{Ventajas y posibles limitaciones de la propuesta.}

La metodología presentada ofrece como ventajas la posibilidad de diagnosticar de manera sistemática la relación entre las fuentes institucionales, los medios y el público, en una sociedad como la cubana, que posee características políticas y contextuales completamente diferentes a otras en las cuales se ha aplicado la agenda setting. A su vez, el estudio de las agendas en el país contribuye a la consolidación de una tradición investigativa iniciada en el año 2010, y que necesita crear bases teóricas, epistemológicas y metodológicas para articularse como una línea coherente con las particularidades del sistema de medios.La propuesta tiene amplias posibilidades de ser aplicada, principalmente en el nivel de pregrado, donde se requiere el desarrollo de habilidades complejas en un período de tiempo relativamente corto.

Sin embargo, las principales limitaciones se encuentran en torno a la disponibilidad de recursos materiales y humanos para la aplicación de técnicas masivas, como las encuestas y en cierta medida los grupos de discusión. Existen otras limitantes relacionadas con el acceso a los materiales periodísticos, pues los medios más estudiados generalmente son aquellos de los cuales se puede recuperar la información fácilmente. Téngase en cuenta que la metodología propuesta está pensada para el ciclo completo del proceso de agenda setting desde las relaciones de las agendas política, mediática y pública, sin embargo se considera que los investigadores pueden abordar de forma fragmentaria el objeto de investigación.

A continuación, se proponen un grupo de temas generales que pueden ser desarrollados por investigadores cubanos a partir de la metodología: 
- Construcción de la agenda mediática en medios locales (estatales) cubanos (se puede particularizar en determinados medios con características específicas, como la televisión, la radio).

- Construcción de la agenda mediática de medios alternativos (digitales) y relación con la agenda pública (medida de forma tradicional o en Internet).

- Análisis del tercer nivel de la agenda entre las fuentes y los medios de comunicación.

- Comportamiento de la agenda política, mediática y pública ante temas eventuales.

- Formación de la agenda de los periodistas en los medios de comunicación.

- Formación de la agenda política y mediaciones que indicen en ella.

- Relación de la agenda de instituciones sociales y el público, o entre estas y los medios de comunicación.

\section{CONCLUSIONES}

Los estudios sobre agenda setting desarrollados hasta la actualidad a nivel internacional revelan una homogeneidad metodológica en cuanto a la medición de objetos y atributos de las agendas política, mediática y pública, los instrumentos estadísticos para calcular las correlaciones estadísticas entre dichos listados temáticos, y en cierta medida en cuanto a la determinación de los factores que inciden en la relación entre estas agendas. Sin embargo, en Cuba se observa una disgregación en cuanto a los métodos y técnicas utilizados, que han ponderado el empleo del enfoque cualitativo para explicar el fenómeno en el país.

La propuesta que se ha expuesto en el estudio concibe la explicación de dicha relación a partir del análisis contextualizado de tres elementos fundamentales: la correlación estadística entre los objetos y atributos de las agendas, las influencias sobre el contenido mediático que inciden en la interacción entre las agendas política y mediática, y las condiciones contingentes que permiten explorar la relación entre esta agenda y la pública, y las características de la formación de esta.

Una metodología para desarrollar estudios sobre agenda setting en el caso cubano puede contribuir desde el punto de vista práctico en la sistematización de las técnicas utilizadas, homogeneizando los principales instrumentos para conducir investigaciones mejor articuladas nacionalmente. 


\section{BIBLIOGRAFÍA}

AELST, P., THESEN, G., WALGRAVE, S., \& VLIEGENTHART, R. (2014): “Mediatization and Political Agenda Setting: Changing Issue Priorities? Mediatization of Politics. Understanding the Transformation of Western Democracies", pp. 200-220.

ANAZCO, F. (2014): "Eso que anda... Un estudio sobre la influencia del rumor en la construcción de la agenda mediática camagüeyana". Tesis de licenciatura. Universidad de Camagüey, Cuba.

ARUGUETE, N. (2015): El poder de la agenda: política, medios y público. Ciudad Autónoma de Buenos Aires, Biblos.

BALBEN, V. (2018): "Agendas en busca de La Fama. Influencia de la regulación y la autorregulación en la construcción de las agendas mediáticas de los órganos de prensa provinciales de Guantánamo en los meses de enero a marzo de 2018". Tesis de licenciatura. Universidad de Oriente, Cuba.

BATISTA, J. (2013): "Por una prensa al derecho". Tesis de Licenciatura. Universidad de La Habana, Cuba.

CABALLERO, D. (2015): "De lo real a la agenda pública. Influencias de las condiciones contingentes en el proceso de formación de la agenda pública en el municipio Santiago de Cuba". Tesis de licenciatura. Universidad de Oriente, Cuba.

CASERMEIRO, A. (2004): Los medios en las elecciones: la Agenda Setting en la Ciudad de Buenos Aires. Buenos Aires, Educa.

CASTILLO, Y. (2015): "El mundo agendado. Influencia de las condiciones contingentes en el establecimiento de la agenda de temas internacionales". Tesis de licenciatura. Universidad de Oriente, Cuba.

COLUNGA, M. (2011): "Mediaciones sobre el contenido de los medios que inciden en la relación entre la agenda mediática del periódico Adelante y la agenda pública de sus lectores potenciales". Tesis de licenciatura. Universidad de Camagüey, Cuba.

FICO, F., \& FREEDMAN, E. (2001): "Setting the news story agenda: Candidates and commentators in news coverage of a governor's race". Journalism \& Mass Communication Quarterly, 78, 3, pp. 437-449.

GALLEGO, J. R., Y ROSABAL, A. (2013): "Las cartas sobre la mesa: Un estudio sobre la relación entre agenda pública y mediática en Cuba: caso Granma”. Signo y Pensamiento, 32, 62, pp. 98-113.

GARCES, R., \& SENEN, A. F. (2017): “¿Cómo se dirige la prensa cubana? Un acercamiento a la gestión de medios, desde la perspectiva de sus periodistas y directivos". Revista Cubana de Información y Comunicación, 6, 12, pp. 84-120.

GARCÍA, J. (2013): Revolución, socialismo, periodismo. La prensa y los periodistas cubanos ante el siglo XXI. La Habana, Pablo de la Torriente.

GARCÍA, J. (2018): ¿Qué periodismo queremos? Cuba, Pablo de la Torriente.

GHANEM, S. I., \&WANTA, W. (2001): “Agenda-setting and Spanish cable news". Journal of Broadcasting \& Electronic Media, 45, 2, pp. 277-289.

GUANCHE, J. C., GENTILI, P., \& SAFORCADA, F. (2013): Estado, participación y representación políticas en Cuba. CLACSO.

GUO, H. TIEN VU, \& MCCOMBS, M. (2012): “An Expanded Perspective on AgendaSetting Effects. Exploring the third level of agenda setting". Revista de Comunicación, 11, pp. 51-68.

GUTIÉRREZ, C. (2017): "Radiando entre agendas: un acercamiento al fenómeno de Intermedia Agenda Setting en las emisoras radiales de la provincia Santiago de Cuba." Tesis de licenciatura. Universidad de Oriente, Cuba. 
HERNÁNDEZ, R., FERNÁNDEZ, C. \& BAPTISTA, P. (2014): Metodología de la Investigación (Sexta edición). México, McGraw Hill.

LANDETA, J. (1999): El método Delphi. Una técnica de previsión del futuro. España, Ariel.

LASSALLE, I. (2017): “Más allá de la reiteración. Relación entre objetos y atributos de la agenda mediática del periódico Granma y las agendas de ocho periódicos provinciales en el año 2016". Tesis de licenciatura. Universidad de Oriente, Cuba.

LIPPMANN, W. (1922): La opinión pública, Buenos Aires, Compañía General Fabril Editora.

LUGONES, M. \& SALADRIGAS, H. (2016): "La investigación en comunicación en Cuba: una caracterización desde lo institucional, cognoscitivo y cultural". Prisma. com, 31, pp. 84-96.

MARTÍNEZ, A. R., \& DUEÑAS, L. (2015): “¿Qué dice Cuba? Un estudio sobre la construcción simbólica de la opinión pública en Cuba Dice”. Tesis de licenciatura. Universidad Central de Las Villas, Cuba.

MCCOMBS, M. \& VALENZUELA, S. (2014): Agenda-Setting Theory: The Frontier Research Questions. Estados Unidos, Oxford handbooks online.

MCCOMBS, M. (1981): "Setting the agenda for agenda-setting research: An assessment of the priority ideas and problems". Mass communication review yearbook, 2, pp. 209-211.

MCCOMBS, M. (1993): "The evolution of agenda-setting research: Twenty-five years in the marketplace of ideas". Journal of Communication, 2, 43, pp. 125-160.

MCCOMBS, M. (2006): Estableciendo la agenda: el impacto de los medios en la opinión pública y en el conocimiento. España, Paidós.

MCCOMBS, M., \& SHAW, D. (1972): "The agenda-setting function of mass media. Public opinion quarterly", 36, pp. 176-187.

MCCOMBS, M., \& SHAW, D. L. (1993): "The evolution of agenda-setting research: twenty-five years in the marketplace of ideas". Journal of communication, 43, 2, pp. 58-67.

MCCOMBS, M., SHAW, D. L., \& WEAVER, D. H. (2014): "New directions in agendasetting theory and research". Mass communication and society, 17, 6, pp. 781-802.

MUÑIZ, V. \& FONSECA, R. Á. (2015): "Caracterización de las agendas mediática y pública en las provincias cubanas entre 2011 y 2014: el caso de Santiago de Cuba". Signo y Pensamiento 34, 67, pp. 76-92.

MUÑIZ, V. (2013): "Viaje al centro de la agenda. Influencias en la construcción de las agendas mediáticas de los órganos de prensa provinciales de Santiago de Cuba". Tesis de licenciatura. Universidad de Oriente, Cuba.

MUÑIZ, V., FONSECA, R. Á. Y CASTILLO, Y. (2015): “Condiciones contingentes en el establecimiento de la agenda mediática sobre temas internacionales en Cuba. Casos Granma y Noticiero Nacional de Televisión". Question 1, 48, pp. 460-477.

OLLER, M. \& CHAVERO, P. (2015): "La percepción de los factores de influencia de los periodistas dentro de la cultura periodística de Ecuador". Anuario Electrónico de Estudios en Comunicación Social "Disertaciones", 8, 1, pp. 81-104.

PEÑA, R. A. A. (2015): "La Agenda setting y sus fuentes en la radio durante un proceso electoral en Colombia". Comunicación y Medios, 31, pp. 171-185.

QUIALA, H. (2015): "Del hecho a la noticia. Relación que se establece entre la agenda mediática de los órganos de prensa provinciales de Santiago de Cuba y la agenda pública del territorio durante el año 2014". Tesis de licenciatura. Universidad de Oriente, Santiago de Cuba. 
RAMOS, R. (2017). "La voz del pueblo. Establecimiento de la agenda pública respecto a temas experienciales en Santiago de Cuba durante el año 2016". Tesis de licenciatura). Universidad de Oriente, Cuba.

RODRÍGUEZ, R. (2004): Teoría de la Agenda-Setting. Aplicación a la enseñanza universitaria. Madrid, Observatorio Europeo de Tendencias Sociales.

SALADRIGAS, H., \& OLIVERA, D. (2011): "La investigación en Comunicación.: Su lugar en Cuba. Redes.com: revista de estudios para el desarrollo social de la Comunicación", 6, pp. 343-363.

SHOEMAKER, P. \& REESE, S. (2016): “A Media Sociology for the Networked Public Sphere: The Hierarchy of Influences Model”. Mass Communication and Society, 19, 4, pp. 389-410.

SILVA, E. (2015): "A influência da televisão nos debates de sala de aula: uma análise com base na hipótese de Agenda-Setting". Tesis de maestría. Universidade Federal de Goiás, Brasil.

STROMBACK, J., \& KIOUSIS, S. (2010): “A new look at agenda-setting effects: Comparing the predictive power of overall political news consumption and specific news media consumption across different media channels and media types". Journal of Communication 60, pp. 271-292.

VALENZUELA, S., \& ARRIAGADA, A. (2009): “Competencia por la uniformidad en noticieros y diarios chilenos, 2000-2005". Cuadernos de información, 24, pp. 41-52.

VIDAL, J.R. (2017): "Retos para una política pública de comunicación en Cuba". En SIERRA, F. \& VALLEJO, R.E. (eds). Derecho a la comunicación: procesos regulatorios y democracia en América Latina. Ecuador: Ciespal, pp. 215-240.

WALGRAVE, S., \& AELST, P. (2004): “The Mass Media's Political Agenda-Setting Power: Towards an Integration of the Available Evidence". Paperfor APSA Conference, Chicago. 
